\title{
Correction to: The Reduced Spinless Salpeter Wave Equation for Bound State Systems
}

\author{
Thabit Barakat $^{1}$ (1) $\cdot$ Haifa I. Alrebdi ${ }^{2}$
}

Published online: 8 June 2021

(c) Sociedade Brasileira de Física 2021

\section{Correction to: \\ Brazilian Journal of Physics (2021) 51:796-802 \\ https://doi.org/10.1007/s13538-021-00874-y}

In the original online version of the article Haifa I. Alrebdi's given name was misspelled. The original article has been corrected.

Publisher's Note Springer Nature remains neutral with regard to jurisdictional claims in published maps and institutional affiliations.

The original article can be found online at https://doi.org/10.1007/ s13538-021-00874-y.

Thabit Barakat

tbarakat@ksu.edu.sa

Haifa I. Alrebdi

hialrebdi@pnu.edu.sa

1 Department of Physics, King Saud University, Riyadh 11451, Saudi Arabia

2 Department of Physics, Princess Nourah bint Abdulrahman, University, Riyadh 11671, Saudi Arabia 